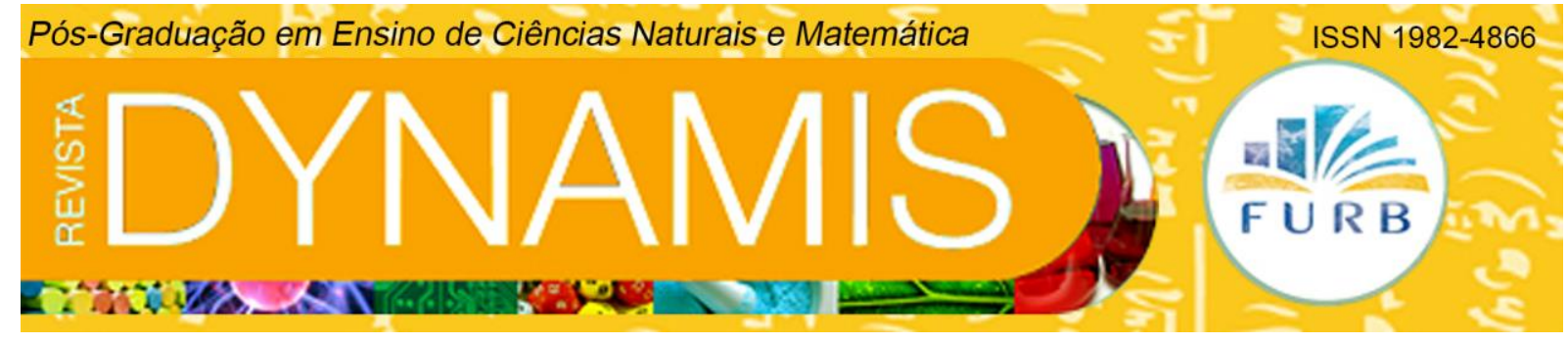

\title{
ESTUDO SOBRE VULCÕES NO CLUBE DE CIÊNCIAS: ANÁLISE MICROGENÉTICA DO PROCESSO DE ENSINO E APRENDIZAGEM
}

Study on volks in the club of sciences: microgenetic analysis of the teaching and learning process

Graciele Alice Carvalho Adriano

Mestre em Educação

Docente no Ensino Superior - UNIASSELVI

Assistente técnica pedagógica na Rede estadual de Santa Catarina carvalho.graci@gmail.com 


\title{
Resumo
}

Socializamos nesse artigo um estudo cujo objetivo foi analisar um episódio de aprendizagem e desenvolvimento de crianças, a mediação docente e semiótica em um Clube de Ciências, no estudo sobre vulcões. A pesquisa foi realizada com uma turma de estudantes de uma escola da rede estadual de ensino de Santa Catarina, na cidade de Blumenau, participante do projeto de Escola Pública Integral - EPI. Utilizamos o método investigativo da pesquisa sociocultural (WERTSCH, 1998), de cunho qualitativo, com abordagem na análise microgenética (GOÉS, 2000). Nossa intenção consistiu em analisar teoricamente, a partir da escola histórico cultural (VIGOTSKI, 2009; 2010), as videogravações realizadas durante a aula no estudo do tema vulcões. A medida que as interações ocorriam sob a mediação da professora, interpretou-se ao analisar minuciosamente os diálogos e ações das crianças na videografia, indícios do desenvolvimento da Zona de Desenvolvimento Proximal (ZDP), com mudanças nas funções psicológicas superiores, mas precisamente no pensamento verbalizado, indicando o desenvolvimento de alguns conceitos científicos pelos estudantes.

Palavras-chave: Processo de ensino e aprendizagem. Mediação docente e semiótica. Zona de Desenvolvimento Proximal.

\begin{abstract}
In this article, we present a study whose objective was to analyze an episode of children's learning and development, teaching and semiotic mediation in a Science Club, in the study of volcanoes. The research was carried out with a group of students from a school of the state education network of Santa Catarina, in the city of Blumenau, participant in the project Public School Integral - EPI. We used the qualitative research method of sociocultural research (WERTSCH, 1998), with an approach in microgenetic analysis (GOÉS, 2000). Our intention was to analyze, theoretically, from the historical cultural school (VIGOTSKI, 2009; 2010), the video recordings made during the lesson in the study of volcanoes. As interactions occurred under the mediation of the teacher, it was interpreted in a detailed analysis of the dialogues and actions of children in videography, evidence of the development of the Proximal Development Zone (ZPP), with changes in the higher psychological functions, but precisely in the thought verbalized, indicating the development of some scientific concepts by the students.
\end{abstract}

Keywords: Teaching and learning process. Educational and semiotic mediation. Zone of Proximal Development. 


\section{Estudo sobre vulcões no Clube de Ciências: Análise microgenética do processo de ensino e aprendizagem}

\section{INTRODUÇÃO}

As crianças antes de ingressarem na escola tiveram experiências no convívio social, aprendendo sobre o mundo de acordo com a cultura ao qual estão inseridas. Assim, alguns aspectos da aprendizagem ocorreram muito antes da entrada na escola, conferindo um teor de conhecimento cotidiano, pluralizado socialmente pelos indivíduos que transmitem oralmente na relação entre os pares. A escola consiste então, um espaço de aprendizado dos conhecimentos sistematizados, socialmente constituído na imersão heterogenia das formas de viver e conceber o mundo dos que ali dividem espaço. Ou seja, na construção de conhecimentos ditos científicos, aqueles acordados pela comunidade científica e determinados como válidos de acordo com a conjuntura social, estão também os socialmente construídos. Aprendizagens que acontecem na escola, nas aulas, na diversidade de projetos e programas oriundos das políticas públicas, que envolvem os estudantes e comunidade escolar.

Assim, nossa intenção do estudo partiu da necessidade de aprofundarmos a respeito das aprendizagens dos saberes científicos pelas crianças e como acontecem às relações entre pensamento e linguagem, tendo-se como cenário um Clube de Ciências como espaço não formal de educação científica na escola. A pesquisa foi realizada em uma escola da Rede Estadual do Ensino, na cidade de Blumenau, participante do projeto de Escola Pública Integral - EPI. Como integrantes diretos de nossa pesquisa temos 33 crianças de sete a oito anos, matriculadas no segundo ano do Ensino Fundamental e a professora responsável pela disciplina de Iniciação à Pesquisa. A partir desta disciplina, organizamos e implantamos o Clube de Ciências nesta escola.

O EPI consiste num dos espaços assegurados nos projetos e programas respaldados pela Lei de Diretrizes e Bases - LDB, quando diz respeito a Educação Básica (BRASIL, 1996) e aponta como objetivo a formação do cidadão incluindo entre outros aspectos, a compreensão do mundo natural e social, o desenvolvimento da aprendizagem e a formação de atitudes e valores. Tem-se como pressuposto teórico a aprendizagem como movimento fundamental que promove o desenvolvimento das crianças a partir da internalização dos conhecimentos científicos na atividade. Portanto, nosso foco investigativo esteve no acompanhamento e compreensão das interações sociais de produção (VIGOTSKI, 2009; 2010) possíveis e que se constituem entre o professor, o conhecimento e suas crianças, a partir de um processo histórico, caracterizado na implantação e desenvolvimento de um Clube de Ciências, a partir da disciplina de Iniciação Científica. Compreendemos a escola como instituição que pode incentivar e aperfeiçoar as interações sociais de produção objetivada na formação das crianças como cidadãs imersas na cultura.

Os Clubes de Ciências, como um dos movimentos escolares, consistem em espaços não formais, organizados para que os estudantes tenham a possibilidade de propor, discutir e aprofundar suas curiosidades e inquietações a respeito das questões relacionadas aos fenômenos da natureza e das tecnologias, que pode ter como ponto de partida a realidade circundante e até planetária. A aprendizagem por meio de investigações escolhidas pelos clubistas, (MENEZES et al., 2014; LONGHI e SCHROEDER, 2012) compreende um processo que os estudantes são conduzidos a patamares mais elaborados de conhecimento, o que caracteriza uma cultura própria da ciência, no qual refletem sobre situações que afetam suas vidas e a do planeta. De acordo com Chassot (2001, p. 38), "[...] poderíamos considerar a ciência como o conjunto de conhecimentos que facilitariam aos homens e mulheres fazer uma leitura do mundo onde vivem, [...] entendessem as necessidades de transformá-lo, e transformá-lo para melhor". Enfim, consiste na possibilidade dos estudantes em pensar a 
partir dos conhecimentos científicos, em agir de modo a propor melhorias às dificuldades encontradas no cotidiano, estabelecendo possíveis relações entre a teoria e prática, um aspecto determinante nas discussões que acontecem nos encontros do Clube de Ciências.

Desta forma, pretendemos ressaltar um dos movimentos, uma aula ou encontro com alguns conceitos das crianças e professora sobre o assunto escolhido pela turma para estudo, os vulcões. Primeiramente submeter ao método investigativo da pesquisa sociocultural (WERTSCH, 1998), de cunho qualitativo, com abordagem na análise microgenética, na construção de dados que necessitam de atenção aos mínimos detalhes e no recorte de episódios interativos, com a análise voltada para atuação dos indivíduos, as relações intersubjetivas e suas condições sociais, ocasionando um relato minucioso dos acontecimentos (GÓES, 2000). Nossa intenção consiste em fomentar uma discussão a partir da base teórico conceitual da escola histórico cultural, proposta pelo bielorrusso Lev S. Vigotski $(2009 ; 2010)$, nas videogravações realizadas durante as aulas, em especial a que foi escolhida dentre as demais e apontar: como se deu o desenvolvimento e aprendizagem das crianças, a mediação docente e semiótica a partir de uma aula sobre os vulcões.

Partimos da proposição em aprofundar questões relacionadas a aprendizagem conceitual da criança e como se estabelece a relação do pensamento e linguagem, no desenvolvimento de um tema a partir da mediação da professora. Vigotski (2009; 2010), por meio de suas contribuições teóricas que caracterizam a escola histórico cultural, aclara os aspectos associados à construção das funções psicológicas superiores e o papel da cultura neste processo, ou seja, o específico e importante papel da escola na construção da subjetividade. Acrescenta, ainda, o aprofundamento da relação do indivíduo com o meio social, mediada pela internalização dos significados historicamente construídos e o papel da linguagem neste processo.

\section{PROCEDIMENTOS METODOLÓGICOS E ANÁLISE MICROGÊNETICA: ALGUMAS CONSIDERAÇÕES}

Nossa pesquisa contou com uma turma de 33 crianças matriculadas no segundo ano do ensino fundamental e a professora responsável pela disciplina de Iniciação Científica, em uma escola da Rede Estadual do Ensino, na cidade de Blumenau (SC), participante do projeto de Escola Pública Integral - EPI. A partir desta disciplina, que aconteceu no contraturno, organizamos e implantamos o Clube de Ciências na escola. Desse modo optamos em apresentar um excerto de uma pesquisa mais ampla orientada para dissertação, sendo que escolhemos um encontro dentre os realizados no decorrer dos cinco meses desde a observação da turma até a implantação do clube. O que nos motivou na escolha entre uma e outra aula partiu do ensejo em observar como se deu o desenvolvimento da ZDP, o processo de ensino e aprendizagem, e a função da professora como mediadora do conhecimento, considerando a interação da professora com a turma. A aula escolhida apresenta uma atividade que envolveu uma prévia pesquisa das crianças sobre o assunto de estudo, os vulcões.

As crianças ao serem instigadas a pesquisarem sobre o assunto pela professora lembraram o uso da internet e do site de busca do Google para procurar sobre o assunto, associando ao auxílio de conviventes mais experientes o acesso a equipamentos, como microcomputadores, notebooks, tablets e celulares. Apesar da turma se encontrar, naquele momento, em processo de alfabetização e assim sentirem dificuldades quanto à língua escrita, solicitaram que fosse escrito no quadro a palavra "vulcão" para o acesso em casa. Assim, as aulas foram observadas e videogravadas, sendo uma submetida à análise microgenética 


\section{Estudo sobre vulcões no Clube de Ciências: Análise microgenética do processo de ensino e aprendizagem}

objetivando-se identificar conceitos espontâneos e científicos, relacionados ao tema de investigação, desenvolvidos pela crianças no Clube de Ciências; analisar os amplificadores culturais utilizados pela professora no Clube de Ciências; apreender indicadores de aprendizagem e desenvolvimento das crianças a partir das atividades no Clube de Ciências, considerando-se as dimensões conceitual, procedimental e atitudinal.

Schroeder, Ferrari e Maestrelli (2013) elucidam a análise microgenética como uma abordagem histórico cultural e semiótica dos processos humanos, genética quando considera as relações com o passado, presente e futuro, na busca pelas relações entre os acontecimentos mais precisamente em "como aconteceu" ao invés de "o que aconteceu". Micro no sentido não exclusivamente por indicar um curto período, apesar da escolha do tempo variar de acordo com o interesse do pesquisador, mas em analisar o processo de mediação que utiliza os sistemas de signos para a comunicação humana, resultando no discurso (WERTSCH, 1998).

Vigotski (2009) propõe através do método de pesquisa que desenvolveu, investigar as relações entre pensamento e linguagem, analisando as formações psicológicas subjacentes a decomposição a totalidade complexa em unidades, considerando a unidade um produto de análise, a micro parte relativa a macro dimensão do episódio, diferente de segmentar a totalidade em elementos e dissecá-los. Compreende a unidade como fonte de todas as propriedades intrínsecas ao todo, como partes indissociáveis dessa unidade, ou seja, "[...] método de análise que desmembra em unidades, [...] que essa unidade pode ser encontrada no aspecto interno da palavra: no seu significado" (VIGOTSKI, 2009, p. 8). Dessa forma, pretendemos investigar o sentido da linguagem na vertente histórico cultural que se ocupa no estudo das relações, segundo Vigotski (2009, p 16-17) revelam "[...] o movimento direto que vai da necessidade e das motivações do homem a um determinado sentido do seu pensamento, e o movimento inverso da dinâmica do pensamento à dinâmica do comportamento e à atividade concreta do indivíduo". Em suma, no entendimento das relações do movimento inter ao intrapsíquico, mediado pelas relações que transformam o indivíduo através da ação do outro, respaldado na resposta desse por meio da comunicação dialógica ao outro. Ou seja, incide no desenvolvimento do indivíduo aspectos referentes as aprendizagem de novos aspectos por meio da interação com o outro, e por meio da comunicação surgem as intersubjetividades ou um entendimento compartilhado (WERSTCH, DEL RÍO, ALVAREZ, 1998).

Os códigos de ética incidem na garantia da segurança e privacidade da identidade dos envolvidos na pesquisa. A confidencialidade da informação consiste no principal procedimento de resguardar a privacidade e intimidade, a segurança dos entrevistados não sofrerem danos e nem incômodos indesejáveis desde a abordagem inicial à elaboração dos relatórios e possíveis publicações (ESTEBAN, 2010). Desse modo, optamos em alterar os nomes das crianças a fim de preservar a identidade, preservando a fidedignidade das falas e fatos ocorridos que envolveram o complexo processo de ensino e aprendizagem da turma e professora.

\subsection{TRANSCRIÇÃO DO ENCONTRO DA TURMA NO CLUBE DE CIÊNCIAS}

As crianças estavam ansiosas e nós, também, com a possibilidade de realizarmos um experimento que exemplificaria um vulcão em erupção. Como a sala de aula do segundo ano apresentava espaços restritos que impediam a movimentação das carteiras, utilizamos o espaço do refeitório, utilizando duas mesas para que as crianças se acomodassem adequadamente para as observações, que incluíam a montagem com os materiais trazidos pela 
professora (figura 1). A turma estava agitada, suas vozes se confundiam em comentários animados com a possibilidade de assistirem a um experimento, em especial um vulcão que entraria em erupção.

Apresentamos, no diálogo do evento, a explicação da professora sobre os elementos e procedimentos para a construção da maquete do vulcão. Em meio a falas exclamativas, quase sempre exaltadas, revelando a ansiedade das crianças que estavam participando, pela primeira vez, de um experimento. Uma das crianças chegou a perguntar o seria uma maquete, outras estavam preocupadas com a possibilidade de o vulcão "explodir" o local onde estavam, possivelmente associando às erupções assistidas nos vídeos ou até mesmo à imagem do cientista desenvolvendo misturas explosivas. Campos e Nigro (1999, p. 142) recomendam demonstrações "[...] para ilustrar uma exposição teórica do professor, permitindo que os alunos conheçam, de forma mais palpável, as teorias abstratas". Os autores alertam para o fato de não constituírem a única atividade sobre o assunto como um resumo das estratégias de ensino, mas como finalidade bem definida. Nossa intenção permeou a experiência como demonstração, realizada pela professora, para que, no decorrer da elaboração, pudesse explicar o fenômeno a partir de conhecimentos científicos sobre os vulcões, respondendo aos questionamentos que poderiam surgir.

Figura 1 - Experimento realizado pela professora

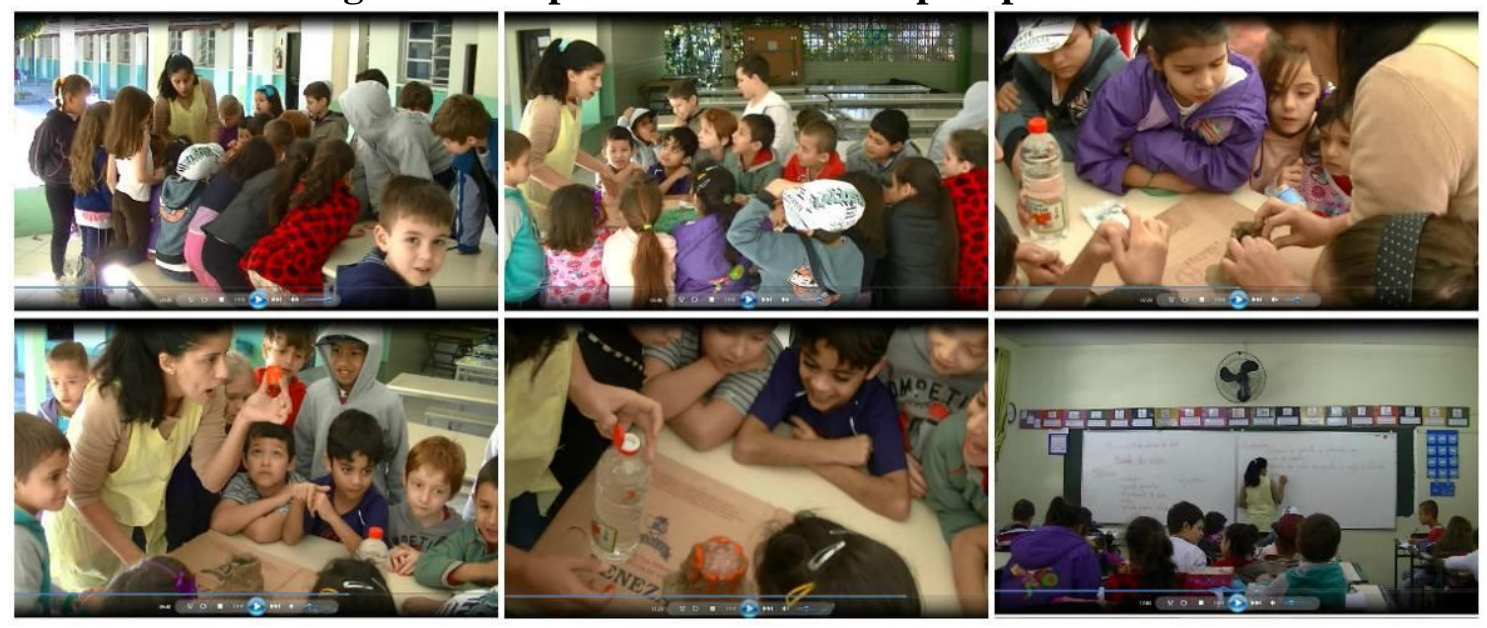

Fonte: Arquivo pessoal da pesquisadora

As crianças questionaram vários aspectos, desde o uso dos ingredientes, quando mostraram surpresa em descobrir que a argila é um tipo de solo, a preocupação que a erupção pudesse derreter a garrafa pet e quando a professora explicou o uso do bicarbonato de sódio na experiência. $\mathrm{O}$ uso da tinta guache vermelha incitou a criatividade das crianças, com alguns comentários como: "daí vai parecer fogo" e "lava", ao vinagre, como ingrediente foi dito que representaria "a bomba na cratera", ao responder à pergunta da professora sobre a função do vinagre na experiência. No momento em que a modelagem do vulcão estava finalizada e a experiência iria acontecer, as crianças ficaram agitadas e algumas observações indicavam a ansiedade presente no momento: "a lava caiu!", "cuidado, cuidado, é lava, é lava!" repetiam as crianças enquanto a mistura reagia, emergindo da parte interna do vulcão e derramando no papelão e mesa uma espuma avermelhada borbulhante.

Analisando a atividade de modelização, retomamos Vigotski (2010), que assevera a respeito do interesse da criança, em nosso caso, o interesse sobre o fenômeno da erupção vulcânica. A respeito desta questão, diz que, para que o objeto se torne interessante, ele deve 


\section{Estudo sobre vulcões no Clube de Ciências: Análise microgenética do processo de ensino e aprendizagem}

estar vinculado a alguma coisa do nosso interesse, algo já conhecido, e ao mesmo tempo deve conter algumas formas novas de atividade, senão continuará sem dar resultados. De acordo com Vigotski (2010, p.117), antes de o professor explicar uma nova atividade atribuindo um "novo conhecimento à criança ou implantar nela uma nova reação, é necessário que se tenha a preocupação de preparar o terreno para elas, ou seja, estimular o respectivo interesse". Portanto, para colocar esse objeto ou fenômeno em uma relação pessoal com a criança, faz-se necessário tornar o seu estudo assunto pessoal da criança. Portanto, poderemos estar certos do êxito. A ansiedade expressa pelas crianças também revelou grande dose de imaginação sobre o que poderia acontecer no modelo de vulcão. Vigotski (2009b) lembra que a imaginação está relacionada a dois aspectos que se relacionam, o intelectual e emocional, e que ambos movem a criação humana. A partir das hipóteses levantadas, podemos identificar o pensamento sincrético, que está relacionado à etapa do desenvolvimento caracterizado na relação direta que a criança estabelece com o meio social (VIGOTSKI, 2010), justificando uma intencionalidade para entender e fazer parte do mundo adulto. Entretanto, a compreensão infantil baseada num modo subjetivo de explicar as situações que vivem ou observam servirá de base para uma seleção futura correspondente à realidade, verificados na prática (VIGOTSKI, 2009b). Nesse sentido, quando as crianças associaram a espuma vermelha com a lava vulcânica, estabeleceram relações imaginativas com o que haviam assistido no vídeo à demonstração feita pela professora. Logo, evidenciamos o medo demonstrado pelas crianças em tocar a mistura, insinuando que poderia queimar algo ou alguém, tamanha a relação estabelecida entre o real e o imaginário, próprio para esta idade. Por tudo isso, relatamos parte do episódio, apresentando excertos dos diálogos, justificando que, talvez, não darão conta de representar a emoção da turma em participar desta atividade.

José - A gente vai fazer o vulcão?

Caique - $O$ vulcão vai explodir na cara de todo mundo?

José - A gente vai fazer o vulcão?

Prof. - Olha só tudo o que a gente vai precisar.

Leonardo - Lava! (Gritou apavorado)

Prof. - Ei, segundo ano, presta atenção aqui! A professora vai fazer uma maquete, representando o vulcão.

Gabriel - O que é maquete?

Prof. - Maquete é...

Gomes - É por causa do vulcão?

Guilherme - Vulcão.

Prof. - Maquete é uma coisa menor. Você vai fazer. Quando vocês vão no shopping, não tem umas casinhas bem pequeninas, prédios, num quadrado? Isso é uma maquete. Então olha só, ei segundo ano. Nós vamos precisar de guache, vinagre..

Gabirel - Vinagre?

Prof. - Uma garrafinha vazia. E argila, tá? Barro.

Leonardo - Barro?

Gabriel - Vulcão, vulcão, vulcão!

Prof. - Isso aqui é para se colocar, os padeiros colocam no bolo para ele ficar fofinho. É bicarbonato de sódio. Também é um remédio, tá?

Caique - Bicarbonato de sódio, hahaha!

José - Cuidado com o sódio!

Prof. - A garrafa vai representar o quê? Vai representar o interior do vulcão. Pessoal! Lembrando que não vai explodir, não vai acontecer nada. É uma representação.

Caique - E se pegar tudo e fazer fogo?

Monica - Dá medo!

Prof. - Olha só! (Levantando a garrafinha de água cortada ao meio) Vai ser dentro do vulcão. 


\section{Graciele Alice Carvalho Adriano}

Natalia - O profe está muito duro. (Referindo a argila sendo moldada pela professora).

(...)

Gomes - Olha que vulcão doido que a professora está fazendo!

Gabriel - Olha o vulcão!

Prof. - Então isso aqui pessoal, lembra que nós vimos na imagem.

Adriele - Isso é um vulcão, profe?

José - Vai derreter a garrafa.

Adriele - Isso é por dentro do vulcão, né profe?

Prof. - É, a garrafa representa lá dentro do vulcão, né?

Gomes Kiko chaves - O profe, daí a gente vai colocar o guache lá dentro do vulcão e daí vai sair lava.

Adriele - Não a gente vai colocar vinagre...

Gomes - Daí vamos colocar tinta guache...

José - Daí vai parecer fogo!

Adriele - Não vai!

Nicolau - Daí ele vai explodir. Ele não explode assim (elevando as mãos para cima, imitando uma explosão), só vai... só vai sair.

(...)

Caique - Daí a tinta vai espirrar aqui e cai (apontando com o dedo para a entrada do vulcão).

Prof. - Pronto. Assim é o vulcão, mais ou menos, por fora, né. A terra, lá dentro lembra que há um buracão.

Gabriel - Ô prô, isso aqui é para quê?? (Apontando para o vinagre).

Caique - Vinagre, vinagre, isso aí é para botar no vulcão!

Prof. - Olha só. Nós vamos colocar a tinta. A tinta, pessoal, o guache vai ...

Caique - Vai colocar tudo dentro do vulcão, depois pum na nossa cara!

Prof. - O guache vai representar o quê?

Leonardo - A lava.

Prof. - Viu, eu acertei!

Prof. - A lava.

Leonardo - O vinagre vai representar, ele vai representar a bomba na cratera.

(...)

Prof. - Ele acontece o quê? O bicarbonato mais o vinagre vai fazer uma coisa.

Natalia - Coloca tudo prô. (No momento em que a professora derrama o bicarbonato dentro do pedaço da garrafa).

Gomes - Não pode tudo.

Prof. - Agora vamos lá, vamos misturar. Um, dois, três.

Paulo - Que cheiro ruim!

Prof. - Cheiro de vinagre.

Caique - Coloca mais prô.

Paulo - A lava caiu.

Prof. - Isso aí é como se fosse o vulcão entrando em erupção, a lava vem lá de dentro, lá do centro da Terra, vem para cima e derrama, tá? Aqui, em uma cidade.

Gabriel - É uma cidade?

Caique - Coberta de lava!

Crianças - Coloca mais. Bota mais. (Ficavam pedindo).

Caique - Coloca tudo profe.

Adriele - Não, ela vai colocar aos poucos, né prô? (gritavam enquanto a mistura esparramava pelo papelão em direção a mesa).

Crianças - É lava, é lava!

(...) 


\section{Estudo sobre vulcões no Clube de Ciências: Análise microgenética do processo de ensino e aprendizagem}

No decorrer do experimento, evidenciamos algumas falas das crianças expressando surpresa e ansiedade para que a "explosão" do vulcão acontecesse. Evidenciamos que, quando a professora juntou as substâncias necessárias para exemplificar a erupção vulcânica, ocasionando a subida do líquido espumoso e vermelho (figura 1), as crianças emitiram sons e gritos, indicando alegria e surpresa. $\mathrm{O}$ relato e as imagens não dão conta de materializar a perplexidade das crianças, suas expressões ao presenciarem a modelização de como seria a erupção de um vulcão. Os diálogos indicam a associação do experimento com a situação real e, usando a imaginação, transformaram a mistura de guache, vinagre e bicarbonato de sódio em lava.

Posteriormente, recolheu a maquete e as crianças ajudaram a trazer os materiais para a sala. Em seguida, a professora entregou os cadernos do Clube para que anotassem os materiais do experimento. Assim, na forma de um texto coletivo, a professora indagou sobre alguns aspectos observados e escreveu no quadro (figura 1), relacionando os itens necessários e os procedimentos da experiência do vulcão. Conduziu a elaboração do texto, questionando sobre a ordem dos fatos, o que foi utilizado e como e assim por diante. As crianças participaram lembrando-se das etapas e dos materiais, a princípio, de forma confusa, trocando a ordem dos fatos. A professora auxiliou e conduziu o relato na medida em que as crianças lembravam os passos da experiência, instigando questionamentos sobre o que viria depois de uma e outra ação. Após a finalização do texto, as crianças fizeram um desenho representando o que viram, como mostra a figura 2. A PCSC (SANTA CATARINA, 2014, p. 170) menciona os benefícios do registro das experiências desenvolvidas em sala de aula e afirma que:

[...] da prática de observações experimentais, em laboratórios formais ou em gravações visuais de experimentos disponíveis em diferentes mídias, em demonstrações em sala de aula ou em observações de campo e de outras circunstâncias extraclasse, nas quais é essencial a prática do registro do observado pelos estudantes, em que também se desenvolve a competência do relato fidedigno.

Vigotski (2009b) comenta a necessidade de mostrar às crianças para quê escrever, no sentido do uso da escrita para a vida social: "O melhor estímulo para a criação infantil é uma organização da vida e do ambiente das crianças que permita gerar necessidades e possibilidades para tal" (VIGOTSKI, 2009b, p. 92), ou seja, mostrar as finalidades sociais do registro escrito, que na atividade sugere a descrição do material e procedimentos da demonstração realizada pela professora, além do desenho.

No planejamento seguinte, discutimos a respeito de uma atividade, a fim de evidenciar alguns entendimentos das crianças sobre o assunto estudado. Gostaríamos de saber como estavam compreendendo os conceitos científicos apresentados até o momento, se conseguiam acompanhar as explicações oriundas dos vídeos e das demonstrações. Para tanto, pensamos em realizar uma atividade conforme a turma conseguisse realizar o registro do assunto, seguida de apresentação da produção organizada em grupos de trabalho. Embora a turma estava em processo de alfabetização, com algumas limitações na produção escrita espontânea, o registro por desenhos (figura 1) seria uma boa opção de produção, pois conseguiriam expressar os entendimentos e depois apresentá-los.

Conforme Azevedo (2013), um dos aspectos da pesquisa-ação voltado à docência traz elementos essenciais referentes à "prática reflexiva" e "professor reflexivo". Para tanto, é fundamental a necessidade do diálogo e da comunicação constituintes da prática colaborativa, permitindo as trocas e a cooperação mútua. Neste sentido, organizávamos os planejamentos considerando as sugestões, bem como as reações das crianças. 


\section{Figura 2 - Textos e desenhos das crianças}

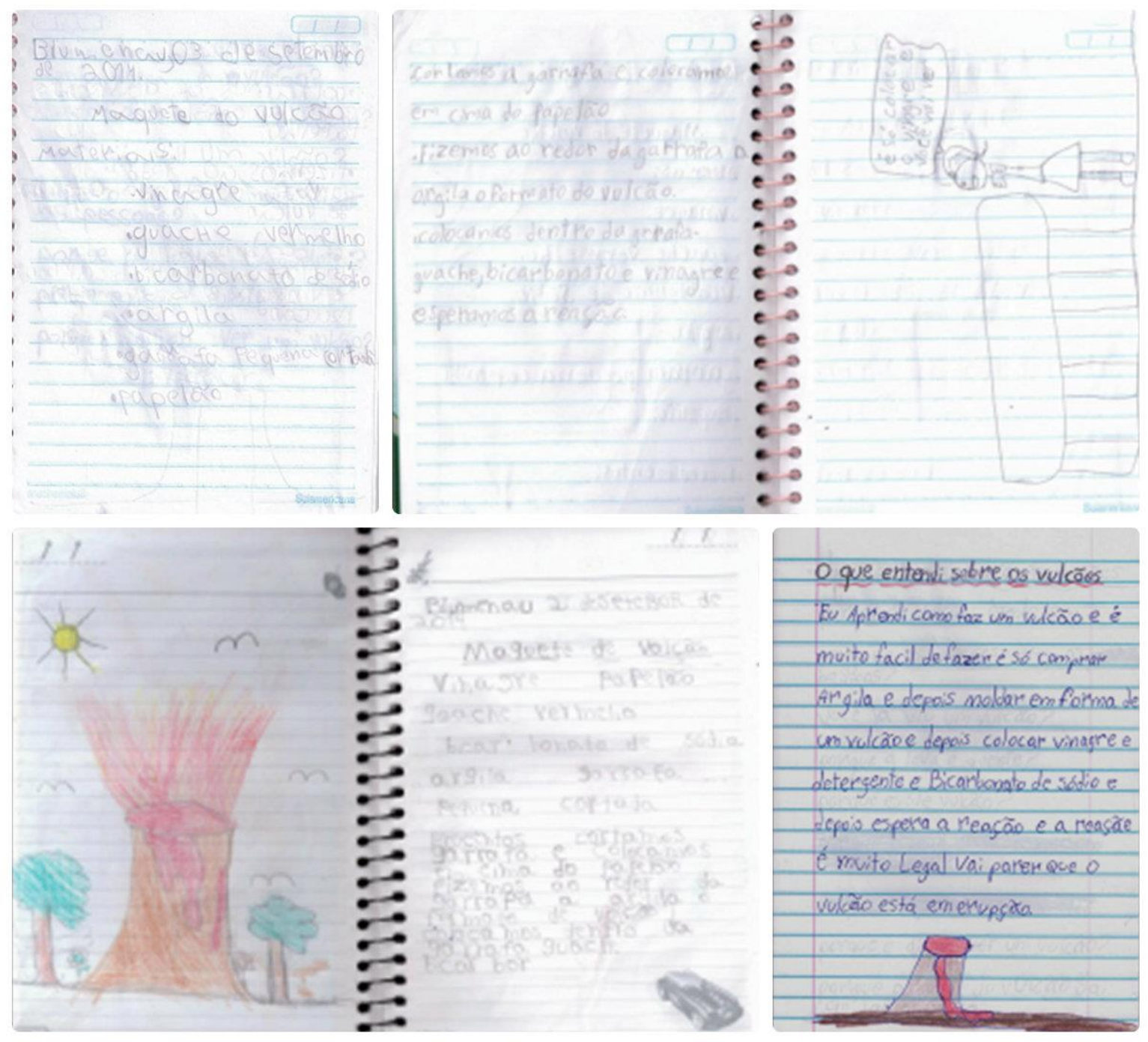

Fonte: Arquivo pessoal da pesquisadora

O início da atividade revelou nervosismo por parte das crianças, uma vez que, além de explicarem, estariam sendo filmadas. Apesar de tranquilizarmos os grupos antes da apresentação, quando se posicionaram perto do desenho, comportaram-se de forma tímida e envergonhada. Apesar do desafio da atividade, considerávamos muito importante, porque poderíamos identificar aspectos relacionados à aprendizagem conceitual e compreensões construídas até então. Para os PCSC (SANTA CATARINA, 2014, p. 156-157):

\footnotetext{
A linguagem compreendida como instrumento psicológico de mediação simbólica é inerente às diferentes áreas de conhecimento. Desta forma, o desenvolvimento da linguagem de caráter científico-tecnológico e matemático se dá em exercícios de diferentes modalidades: oral, escrita, corporal, imagética e sonora, mediada por diferentes metodologias que resultem na produção autoral dos sujeitos da aprendizagem.
} 


\section{Estudo sobre vulcões no Clube de Ciências: Análise microgenética do processo de ensino e aprendizagem}

Uma forma de expressar os entendimentos sobre um determinado assunto incluiu a atividade do desenho, da criação. No que diz respeito a esta importante questão da aprendizagem, Vigotski (2009b, p. 26) apresenta a:

\footnotetext{
[...] lei do signo emocional comum. A essência dessa lei consiste em que as impressões ou as imagens que possuem um signo emocional comum, ou seja, que exercem em nós uma influência emocional semelhante, tendem a se unir, apesar de não haver qualquer relação de semelhança ou contiguidade explicita entre elas. Daí resulta uma obra combinada da imaginação em cuja base está o sentimento ou o signo emocional comum que une os elementos diversos que entraram em relação.
}

São elementos que podem ser originados dos conceitos espontâneos e relacionados aos científicos, de acordo com as explicações com apoio das imagens e os vídeos apresentados. O intenso processo de aprendizagem em sua trajetória na Zona de Desenvolvimento Proximal requer tempos mediatizados para que as crianças consigam compreender, modificar e construir conceitos, conforme seus entendimentos. Lembramos, ainda, que no processo de criação as crianças se utilizam da associação de elementos dissociados e modificados, que podem incluir subjetividades de imagens com as cientificamente objetivas (VIGOTSKI, 2009b).

Pode-se dizer que, ao elaborarem os desenhos, as crianças utilizaram a subjetividade emocional, numa representação conceitual com nuances científicas, quando buscam compreender e reelaborar os próprios conceitos espontâneos. Neste ínterim, as falas das crianças mostraram certo entendimento conceitual, ainda que fizessem uso equivocado de alguns termos, mas já mostrando uma arquitetura conceitual sobre o assunto. Neste sentido, destacamos algumas falas, como: "ele entra em erupção"; "desenhei um vulcão soltando lava, dai eu desenhei a lava"; "eu entendi que ele explode"; "que primeiro ele solta fumaça antes de soltar a lava"; "que eles explodem embaixo da água"; "eu entendi que o vulcão sai fumaça (...) eu entendi que ele sai fumaça, daí ele solta lava, estoura tudo, as pessoas viram rocha, destrói o mundo e ... "blá, blá, blá, e blá, blá, blá" - um colega discordando da parte final da explicação: "[...] Ele não destrói o mundo, só partes...". "Eu entendi que quando eles querem fazer lava, eles sempre soltam fumaça primeiro". Seguiu-se um comentário de uma colega: "as cinzas"; "que o vulcão pode destruir um monte de casas"; "daí quando as pessoas estão aqui, daí viram pedras. Quando estão dormindo, mas quando estão acordadas elas podem fugir ainda da lava". Na discussão entre duas crianças, uma afirma: "eu entendi sobre os vulcões que dormem, mas eles não explodem mais". Outra adverte: "vulcões não tem vida, Aline!", seguindo-se uma resposta: "eu sei". Outro grupo explica a erupção vulcânica: "que os vulcões explodem quando eles estão com raiva".

Nestes diálogos, evidenciamos a manifestação da forma sincrética de entender a realidade, ou seja, o pensamento concreto da criança é o pensamento lógico, no sentido da palavra, mas no nível do pensamento verbal, abstrato, ainda está sujeito ao sincretismo. Desse modo, a criança não compreende as contradições, é incapaz de perceber as relações, utilizando a transdução, um processo de transferência de algo particular para outro, no método fundamental do pensamento. A etapa do pensamento lógico da criança, ainda em desenvolvimento, não domina uma tomada de consciência, porque não compreende o pensar do outro. Assim, também, não tem consciência de si mesmo, do seu pensar - a consciência lógica é fruto da reflexão, estudos e exige certa observação do próprio pensamento, um pensamento capaz de realizar operações lógicas (VIGOTSKI, 1997). No entanto, observamos 
como as crianças estão evoluindo na sua forma de pensar e se comunicar, fruto das atividades desenvolvidas no Clube de Ciências. Desta forma, percebemos, nas explicações das crianças sobre os vulcões, aspectos emocionais condicionados a um fenômeno inanimado, buscando compreender a ação do outro, sobre o que levaria um vulcão a entrar em erupção. Quer dizer, num processo de transdução análogo à transferência das emoções, formas de sentir e agir conhecidas pela criança, a outra situação particular representada pelas particularidades inerentes à sua condição lógica, como em: "eu entendi sobre os vulcões que dormem, mas eles não explodem mais" ou "que os vulcões explodem quando eles estão com raiva".

Apresentamos parte das apresentações feitas pelas crianças, em grupos, com o desejo de expor indicadores de aprendizagem dos conceitos científicos, uma forma de avaliação que preconiza a etapa de aprendizagem e desenvolvimento.

Prof. - Então vamos lá, o nosso assunto estudado é sobre os vulcões. Vocês viram, lá na sala de informática, nós escrevemos e a professora explicou, e aí a professora pediu para a equipe fazer um desenho (...).

Gomes - É que ele explode, entra em erupção se a gente... (continuou falando,com o tom cada vez mais baixo).

Prof. - Mais alto, Gomes, que eu não entendi. Tá, Gomes! Olha aqui para a prô. Ele explode, sai lava e o que mais?

José - Ele entra em erupção.

Prof. - Entra em erupção...

Gomes - E pega fogo ... (risos).

Crianças - (risos).

Prof. - E pega fogo.

Gomes - E sai um monte de larva.

José - Não é larva é lava.

(...)

Prof. - Eu quero que as três expliquem o desenho.

Aline - Eu entendi sobre os vulcões que dormem, mas eles não explodem mais.

Natalia - Vulcões não tem vida, Aline!

Aline - Eu sei...

(...)

Prof. - Ah, não apareceu direito. E o que a Monica e a Adriele entenderam sobre os vulcões.

Monica - Eu entendi que ele explode.

Prof. - Que eles explodem? O que mais?

Prof. - Adriele, o que tu tens para dizer sobre o vulcão? O que você entendeu?

Adriele - Que primeiro ele solta fumaça antes de soltar a lava.

(...)

Prof. - Ah, os dois vulcões Maiara? Maiara o que você entendeu sobre os vulcões?

Maria - Que os vulcões explodem quando eles estão com raiva.

Prof. - Com raiva? Eles explodem quando estão com raiva?

Soraia - Que quando eles explodem, as pessoas viram pedra.

Prof. - As pessoas viram o quê?

Soraia-Pedra!

(...)

Prof. - Luís, me explica o teu desenho. 


\section{Estudo sobre vulcões no Clube de Ciências: Análise microgenética do processo de ensino e aprendizagem}

Leonardo - Eu entendi que o vulcão sai fumaça ... eu entendi que ele sai fumaça, daí ele solta lava, estoura tudo, as pessoas viram rocha, destrói o mundo e blá, blá, blá, e blá, blá, blá.

Jonas - Ah, ele destrói o mundo? Destrói o mundo?

Prof. - Fernando o que você entendeu sobre os vulcões?

Jonas - Ele não destrói o mundo, só partes...

\section{(...)}

Prof. - Expliquem o desenho de vocês agora.

Karina - Aqui é o André que desenhou o vulcão entrando em erupção, aqui.

Prof. - E o que vocês entenderam sobre os vulcões?

Karina - Eu entendi que quando eles querem fazer lava, eles sempre soltam fumaça primeiro.

Prof. - Sempre soltam fumaças primeiro?

Natalia - As cinzas.

Nicolau - As cinzas.

Prof. - E o que mais?

Alexandre - Que o vulcão pode destruir um monte de casas.

Karina - Daí quando as pessoas estão aqui, daí viram pedras. Quando estão dormindo, mas quando estão acordadas elas podem fugir ainda da lava.

Karina - Foi muito bacana desenhar isso aqui.

Prof. - (...) eu quero saber de você o quê você entendeu sobre vulcões.

Natalia - A professora tinha falado naquele dia que a gente estava na sala de informática, que tinha vulcões extintos, a professora falou.

Prof. - E tinha o que mais? $O$ que mais você entendeu sobre os vulcões. O que acontece com o vulcão quando ele vai entrar em erupção?

Natalia - Fumaça.

Prof. - Fumaça e o que mais?

Natalia - Escorre lava.

Prof. - Obrigada Natalia.

Figura 3 - Apresentação dos desenhos
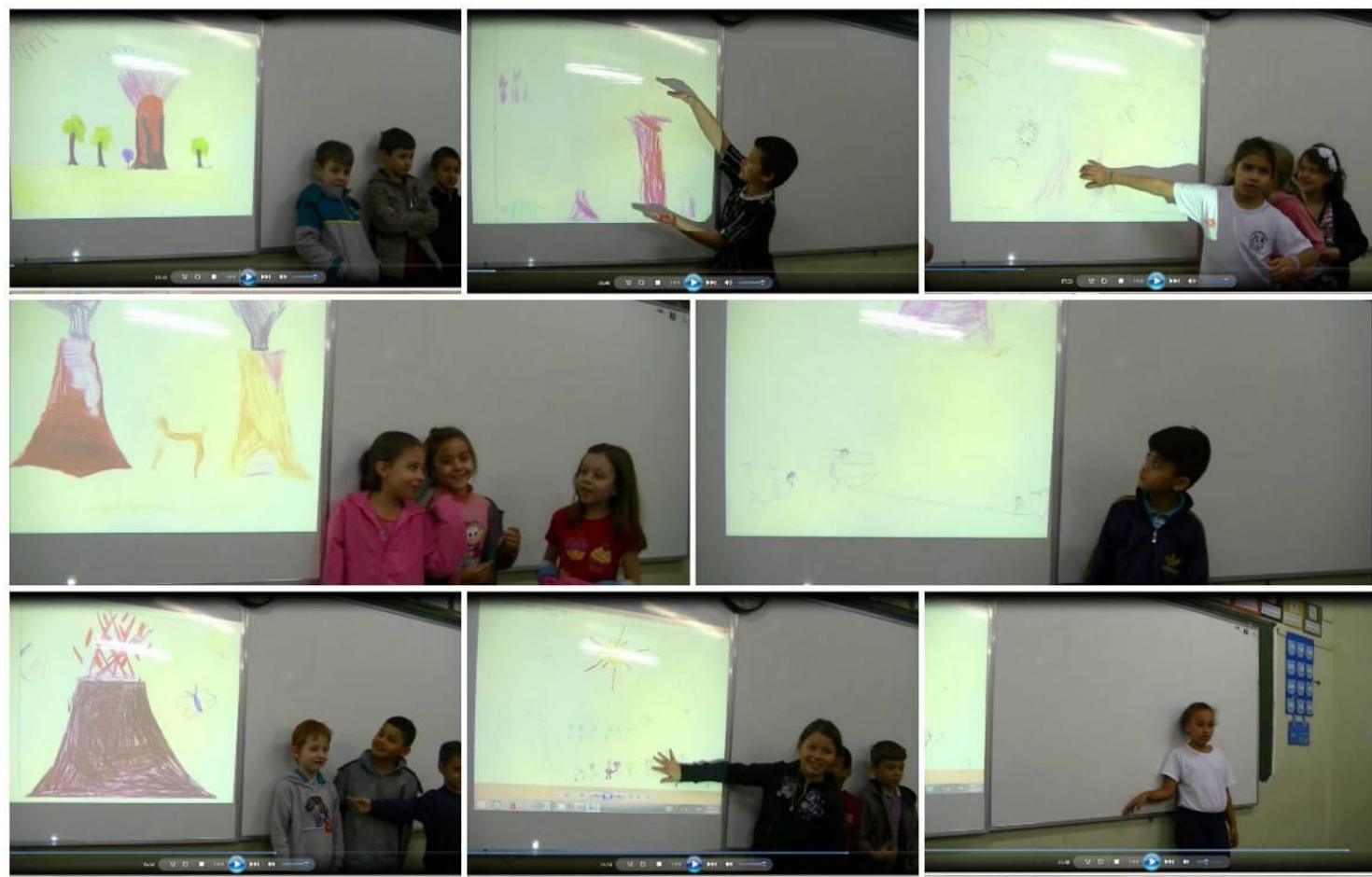
Fonte: Arquivo pessoal da pesquisadora

Durante as apresentações, possivelmente pela timidez, algumas crianças se recusaram a apresentar as suas considerações sobre os vulcões para a turma. Utilizaram-se da linguagem que conheciam e assim misturaram conceitos aprendidos com termos da experiência pessoal em suas explicações. Vigotski (1997) explica que a estrutura do conceito se manifesta no sistema de juízo, no ato do pensamento, que constitui uma formação integral, única, formada por leis próprias, ou seja, "[...] o conjunto sistematizado de juízos constitui certo conteúdo em forma regulada e unida, constitui a união de diversos aspectos do conteúdo" (VIGOTSKI, 1997 p. 26). O autor menciona que "os esquemas sincréticos são também expressões típicas do domínio dos vínculos empíricos e da lógica da percepção, no pensamento da criança. Por isso, a criança confunde o vínculo entre as suas impressões como vínculo entre os objetos" (VIGOTSKI, 2009a, p. 382). Situação percebida nas explicações, incluindo as formas de agir de algumas, quando se recusam a expressar publicamente o pensamento.

A professora interagiu com as crianças, com questionamentos, intencionando mediar uma explicação, a fim de valorizar os conhecimentos da turma. Destacamos Vigotski (2010, p. 448) quando afirma que "para a educação atual não é tão importante ensinar certo volume de conhecimento quanto educar a habilidade para adquirir esses conhecimentos e utilizá-los. E isso se obtém apenas [...] no processo de trabalho". Vigotski (2010) apresenta o professor como um "organizador do meio social", aquele que propicia a relação das crianças com os elementos do meio no sentido de alcançar a mediação entre o conhecimento e as crianças, as crianças entre si e com os signos.

Prosseguindo, a professora sugeriu que as crianças se dividissem em equipes, conversassem sobre o assunto e definissem uma palavra associada ao vulcão para escreverem em uma folha de papel pardo, fixada no quadro branco. Após um tempo para discussão nos grupos, a professora continuou a atividade. Enquanto uma criança escrevia a palavra no papel, outras acompanhavam e inferiam comentários, lembrando os dizeres que haviam acordado no grupo (figura 3). Friedrich (2012) infere sobre os saberes ensinados na escola, de forma que não se reduzam à lógica da transmissão, mas que seja provocado um "poder fazer" pelos estudantes. A autora prossegue, explicando que "o conhecimento não é dado nem adquirido, ele é mostrado, acentuado, demonstrado pelo professor e, a partir dessas operações, ele é construído pela criança" (FRIEDRICH, 2012, p. 114). Análogo ao aprendizado da escrita, a criança, primeiramente, imita, por meio da cópia, o que é mostrado pelo professor. Posteriormente, como na atividade proposta no Clube, as crianças assumem a autoria da construção escrita, uma das possibilidades para materializar o pensamento.

A professora auxiliou os que tiveram dúvidas quanto à escrita de uma ou outra palavra, bem como esclareceu algumas dúvidas que as crianças manifestaram antes de escreverem no papel pardo. Lia em voz alta todas as frases escritas para que todos pudessem ouvir e a palavra solicitada se transformou em frases sobre os vulcões. Quando todos os grupos registraram suas contribuições, colou o cartaz na parede lateral, para que todos pudessem ler e apreciar as contribuições dos colegas. Vigotski (2009a) pondera que as crianças envolvidas em atividade põem em evidência a curiosidade e o desafio e isso faz com que utilizem todos os instrumentos possíveis para encontrar as respostas, o que contribui para a aprendizagem enquanto ser em desenvolvimento.

\section{CONSIDERAÇÕES FINAIS}


A escola, um dos espaços de interação social e aprendizagem apresenta traços culturais e históricos pertencentes a um determinado tempo histórico e cultural. Assim, a observação de uma turma apresenta determinas formas de agir e pensar específicos de um grupo que convive e aprende no cotidiano escolar, mediados sobretudo na ação docente e semiótica. Lembramos que a turma observada apresenta aspectos singulares, com crianças de oito anos em processo de alfabetização, frequentando uma escola em período integral. Uma das disciplinas, Iniciação Científica, contemplou a implantação do Clube de Ciências, aceito e organizado com a turma e a professora do segundo ano de Ensino Fundamental.

Retomamos nosso desafio: analisar um episódio de aprendizagem e desenvolvimento de crianças, a mediação docente e semiótica em um Clube de Ciências, no estudo sobre vulcões. Desta forma, destacamos atenção ao uso dos instrumentos psicológicos no desenvolvimento de uma aula ou encontro, dentre todos os que contemplaram o estudo da dissertação. Consideramos a presença dos recursos e métodos, ou as ferramentas psicológicas nas palavras de Schroeder, Ferrari e Maestrelli (2013) sob a mediação da professora na condução da aula, objetivando a compreensão das crianças sobre o tema estudado - os vulcões.

Logo, a participação das crianças revelaram alguns indícios de mudanças nas funções psicológicas superiores, mas precisamente no pensamento verbalizado, indicando alguns conceitos científicos. Aprendizagens que se desenrolaram nos diálogos, alguns debates entre as crianças, também entre a professora e crianças sobre o assunto. Discussões sobre ideias, conceitos e hipóteses do assunto vulcões, respaldados nas informações ora nos vídeos que haviam assistidos, ora nas explicações da professora. A medida que os diálogos ocorriam sob a mediação da professora, percebeu-se ao analisar minuciosamente os diálogos e ações das crianças na videografia, indícios do desenvolvimento da ZDP.

Segundo a teoria histórico cultural, a aprendizagem não ocorre linearmente, mas em saltos, sendo que em um determinado conceito a criança pode ter compreendido ao ponto de explicá-lo. Entretanto, em outro apresentar enganos conceituais, não limitando o processo de crescimento intelectual a um determinado ponto, mas demonstrando os saltos que ocorrem na forma de compreender. Percebemos na análise do encontro certos avanços de aprendizagem sobre os conceitos científicos dos vulcões, ao mesmo tempo em que aparecem algumas falas relativas ao pensamento sincrético. De fato, o processo de elaboração do pensamento conceitual completa sua fase na adolescência e até esse período, a criança formula suposições baseadas na estrutura mental disponível, muitas vezes de forma eidética.

A análise microgenética como metodologia da análise de um período histórico e cultural, traz a gênese das relações, na mediação docente, semiótica e no uso dos instrumentos psicológicos, possibilitando a compreensão da relação entre os pares, do processo como um todo. Entretanto, a análise não condiciona o "que foi" realizado ou dito no evento analisado, mas evidencia o "como". Cita as falas de forma detalhada para que ao serem lidas e relidas, assim como a visualização da videografia de forma repetida, permite inferir aspectos que possam passar despercebidos na primeira análise. Intencionamos apresentar aspectos que denotam um certo desenvolvimento conceitual científico das crianças, as relações mediadas que ocorreram entre elas, e com a professora, bem como no uso de alguns instrumentos psicológicos.

\section{Referências}


AZEVEDO, M. N. Ensinar Ciências e Pesquisa-Ação: saberes docentes em elaboração. Jundiaí: Paco Editorial, 2013.

BRASIL. Ministério da Educação. Secretaria da Educação Fundamental. Lei de Diretrizes e Bases da Educação. Brasília: 1996. Disponível em < http://portal.mec.gov.br/arquivos/pdf/ldb.pdf> Acesso em: 20 jun 2015.

CHASSOT, A. Alfabetização científica: questões e desafios para a educação. Ijuí: UNIJUİ, 2001.

ESTEBAN, M. P. S. Pesquisa qualitativa em educação: fundamentos e tradições. Porto Alegre: AMGH, 2010.

FRIEDRICH, J. Lev Vigotski: mediação, aprendizagem e desenvolvimento: uma leitura filosófica e epistemológica. São Paulo: Mercado de Letras, 2012.

GÓES, M. C. R. de. A abordagem microgenética na matriz histórico-cultural: Uma perspectiva para o estudo da constituição da subjetividade. Cadernos Cedes, ano XX, n. 50. Abr, p. 9-25, 2000. Disponível em <http://www.scielo.br/scielo.php?pid=s010132622000000100002\&script=sci_arttext $>$ Acesso em: 24 abr. 2015.

LONGHI, A.; SCHROEDER, E. Clubes de Ciências: o que pensam os professores coordenadores sobre ciência, natureza da ciência e iniciação científica numa rede municipal de ensino. REEC. Revista Electrónica de Enseñanza de las Ciencias, v. 11, p. 547-564, 2012.

MENEZES, C. et al. Ações concretas para o desenvolvimento de Clubes de Ciências como espaço de alfabetização científica e ecoformação na educação básica. In: ZWIEREWICZ, M. (coord.). Criatividade e inovação no ensino superior: experiências latino-americanas e européias em foco. Blumenau: Nova Letra, 2014. P. 311-330.

SANTA CATARINA. Governo do Estado. Secretaria de Estado da Educação, Ciência e Tecnologia. Proposta curricular de Santa Catarina: formação integral da educação básica. S. I., S. n., 2014. Disponível em:

<http://www.propostacurricular.sed.sc.gov.br/site/Proposta_Curricular_final.pdf $>$. Acesso em: 12 fev. 2015.

SCHROEDER, E.; FERRARI, N.; MAESTRELLI, S. P. M. O ensino e a aprendizagem dos conceitos científicos no estudo da sexualidade humana: contribuições de Vygotsky para pesquisa em ensino de ciências. Blumenau: Edifurb, 2013.

VIGOTSKI, L. S. A construção do pensamento e da linguagem. São Paulo: WMF Martins Fontes, 2009a.

Imaginação e criação na infância. São Paulo: Ática, 2009b.

Psicologia pedagógica. São Paulo: Martins Fontes, 2010.

Obras Escogidas IV: Desarrollo de los intereses en la edad de transición.

Madrid: Visor Distribuciones, 1997.

WESTRCH, J. V. A necessidade a ação na pesquisa sociocultural. In: WERSTCH, J. V.; DEL RÍO, P.; ALVAREZ, A. (Orgs.).Estudos sociais da mente. Porto Alegre: Artmed, 1998. p. 5671. 